\title{
A three year follow up of preterm infants after moderately early treatment with dexamethasone
}

\author{
C Romagnoli, E Zecca, R Luciano, G Torrioli, G Tortorolo
}

Arch Dis Child Fetal Neonatal Ed 2002;87:F55-F58

See end of article for authors' affiliations

.....................

Correspondence to: Dr Romagnoli, Division of Neonatology, Catholic University of the Sacred Heart, Largo A Gemelli 8 , 00168 Rome, Italy; cromagnoli@rm.unicatt.it

Accepted

24 January 2002

\begin{abstract}
Objective: To assess the effect of moderately early postnatal dexamethasone treatment on growth and neurodevelopmental outcome in preterm infants.

Methods: Thirty preterm infants enrolled in a randomised clinical trial to investigate the effectiveness of moderately early dexamethasone administration in the treatment of chronic lung disease were routinely followed up. Fifteen babies received a total dose of $4.75 \mathrm{mg} / \mathrm{kg}$ over 14 days from the 10th day of life, and 15 babies were untreated. Five infants in each group received open label steroids to facilitate extubation later in their clinical course. Growth and neurodevelopmental outcome are reported. Results: The mean body weight, height, and head circumference as well as the number of babies with anthropometric measurements within normal range were similar in treated and untreated babies. There was no significant difference between treated and control groups with respect to incidence of cerebral palsy, major neurosensory impairment, mean intelligence quotient scores, and behavioural abnormalities.

Conclusions: Postnatal dexamethasone treatment with the schedule used in this study did not impair growth and neurodevelopmental outcome in preterm infants. Data from larger trials have raised major concern that postnatal steroid treatment may increase neurodevelopmental impairment. The full extent of the risk will only be known when more trials have reported follow up data.
\end{abstract}

$\mathrm{P}$ ostnatal dexamethasone has been widely used in the treatment of chronic lung disease (CLD) in preterm infants, and several randomised trials have shown that it rapidly reduces requirements for oxygen and ventilation. However, the long term consequences on mortality and morbidity are less clear, and recent reports have raised concerns that postnatal steroids may cause neurodevelopmental impairment in preterm infants. ${ }^{1-3}$ In animal models, corticosteroids significantly impair cell multiplication in the central nervous system and lung. ${ }^{4}$ Murphy et al, ${ }^{5}$ using advanced magnetic resonance imaging techniques, documented a reduction in the volume of cortical grey matter in preterm infants exposed to postnatal dexamethasone treatment, and this finding is consistent with clinical trials reporting a reduction in head growth and an increase in the rates of cerebral palsy among children who received steroids as compared with controls. The recent systematic review performed by Barrington, ${ }^{6}$ which included eight randomised controlled trials enrolling 679 infants, showed a relative risk for neurodevelopmental impairment among surviving, followed up, treated infants of 1.34 (95\% confidence interval (CI) 1.09 to 1.64$)$ and a relative risk for cerebral palsy of $2.02(95 \%$ CI 1.51 to 2.71 ).

In this study we describe the follow up findings at three years of adjusted age for 30 surviving infants at high risk for CLD who participated in a randomised clinical trial on the moderately early postnatal use of dexamethasone.

\section{MATERIALS AND METHODS}

The original randomised clinical trial was carried out in our neonatal intensive care unit over a 16 month period ending June 1997 in order to evaluate the effect of moderately early dexamethasone administration on incidence and severity of CLD in ventilated preterm neonates.

The study included 30 neonates who were oxygen and ventilator dependent on the 10th day of life and who were at high risk of CLD according to our scoring system. This score is based on gestational age, birth weight, respiratory distress syndrome, grade of respiratory support (in terms of peak inspiratory pressure and inspired oxygen concentration) and some major neonatal complications (pulmonary interstitial emphysema, patent ductus arteriosus, intraventricular haemorrhage $>$ grade 2 , sepsis). A previous study indicated that more than $90 \%$ of infants who had a positive score would develop CLD at 28 days of age. ${ }^{8}$ After informed consent from the parents, the randomisation of eligible infants, obtained by random number allocation, was revealed by opening numbered, sealed envelopes and was carried out at 10 days of life, envisaging 15 neonates for both treatment and control group. The infants in the treatment group received dexamethasone intravenously, $0.5 \mathrm{mg} / \mathrm{kg} /$ day for the first six days, $0.25 \mathrm{mg} / \mathrm{kg} /$ day for the next six days, and $0.125 \mathrm{mg} / \mathrm{kg} /$ day for the last two days of treatment (total dose $4.75 \mathrm{mg} / \mathrm{kg}$ ). In addition, they received intravenous caffeine at a dose of $2.5 \mathrm{mg} / \mathrm{kg} /$ day after a loading dose of $10 \mathrm{mg} / \mathrm{kg}$, from birth and for all the study period. The control group was treated with caffeine only at the same dose and for the same period. The study protocol and consent forms were approved by the ethical committee of the Department of Paediatrics.

Table 1 reports baseline characteristics and major morbidity at discharge from the neonatal intensive care unit. The two groups were similar in every way other than exposure to dexamethasone and incidence of CLD (both at 28 days of life and at 36 weeks of postconceptional age), which was significantly lower in the treated group. Cranial ultrasound scans were performed in all babies on the 1st, 3rd, 7th, and 10th day of life and then every week until discharge. Intraventricular haemorrhage was detected in two treated infants and three control infants; in all cases it was diagnosed in the first week of life. One baby in the treated group showed cystic periventricular leucomalacia on cranial ultrasound scan performed on the 17th day of life; this finding followed the observation of periventricular echodensities seen since the first day of life.

Table 2 shows baseline data with respect to centiles at birth and at discharge from the neonatal intensive care unit as well 
Table 1 Baseline characteristics and major morbidity at discharge of preterm babies treated or not with dexamethasone

\begin{tabular}{lll}
\hline & $\begin{array}{l}\text { Treatment } \\
\text { group } \\
(\mathrm{n}=15)\end{array}$ & $\begin{array}{l}\text { Control } \\
\text { group } \\
(\mathrm{n}=15)\end{array}$ \\
\hline Mean gestation (SD) in weeks & $27.5(1.4)$ & $27.1(1.4)$ \\
Mean birth weight (SD) in g & $850(183)$ & $948(239)$ \\
Male (\%) & $8(53.3)$ & $8(53.3)$ \\
Antenatal steroids (\%) & $7(46.7)$ & $6(40)$ \\
Hyaline membrane disease (\%) & $12(80)$ & $12(80)$ \\
Patent ductus arteriosus (\%) & $11(73.3)$ & $13(86.7)$ \\
Septicaemia (\%) & $6(40)$ & $6(40)$ \\
Necrotising enterocolitis (\%) & $2(13.3)$ & $1(6.7)$ \\
Intraventricular haemorrhage $>$ grade 2 (\%) & $2(13.3)$ & $3(20)$ \\
Periventricular leucomalacia & $1(6.7)$ & 0 \\
Chronic lung disease at 28 days (\%) & $10(66.7)$ * & $15(100)$ \\
Oxygen at 36 weeks (\%) & $5(33.3) *$ & $11(73.3)$ \\
\hline * 0 0.05 compared with control group. & & \\
\hline
\end{tabular}

Table 2 Anthropometry from birth to discharge of preterm babies treated or not with dexamethasone

\begin{tabular}{|c|c|c|}
\hline & $\begin{array}{l}\text { Treatment } \\
\text { group } \\
(n=15)\end{array}$ & $\begin{array}{l}\text { Control } \\
\text { group } \\
(n=15)\end{array}$ \\
\hline \multicolumn{3}{|l|}{ Data at birth } \\
\hline Body weight below 3rd centile (\%) & $2(13.3)$ & $3(20)$ \\
\hline Body length below 3rd centile (\%) & $3(20)$ & $2(13.3)$ \\
\hline Head circumference below 3rd centile (\%) & $2(13.3)$ & $2(13.3)$ \\
\hline \multicolumn{3}{|c|}{ Data at discharge } \\
\hline Body weight below 3 rd centile (\%) & $3(20)$ & $4(26.7)$ \\
\hline Body length below 3rd centile (\%) & $3(20)$ & $2(13.3)$ \\
\hline Head circumference below 3rd centile (\%) & $3(20)$ & $3(20)$ \\
\hline \multicolumn{3}{|l|}{ Anthropometry from birth to discharge } \\
\hline Postconceptional age (weeks) & $41.1(2.0)$ & $41.0(2.0)$ \\
\hline Weight gain $(\mathrm{g} / \mathrm{kg} /$ day) & $18.9(5.0)$ & $19.7(4.1)$ \\
\hline Length gain (cm/week) & $0.82(0.23)$ & $0.95(0.16)$ \\
\hline Head circumference gain $(\mathrm{cm} /$ week) & $0.73(0.22)$ & $0.65(0.23)$ \\
\hline
\end{tabular}

Values are expressed as number $(\%)$ or as mean (SD)

as the gain in weight, length, and head circumference from birth to discharge. There was no significant difference between the two study groups with respect to the incidence of infants with body weight, height, or head circumference below the 3rd centile at birth and at discharge.

Postconceptional age, weight gain, length gain, and gain in head circumference at discharge were not different between the groups.

All the infants studied (15 treated and 15 controls) were enrolled in, and completed, the follow up performed at 36-42 months of adjusted postnatal age. Follow up controls were performed by the same paediatrician (RL) with periodic visits at 3, 8, 12, 24, 36, and 42 months of adjusted age. At each visit, an interim medical history was associated with a physical examination. Weight, supine crown-heel length, and occipitofrontal head circumference measurements were recorded. On the occasion of visits at 3,8, and 12 months of corrected age, a cranial ultrasound scan was carried out; the definition of major cranial ultrasound abnormality was based on published criteria. ' All infants underwent a neurological examination by a paediatric neurologist (GT) to assess motor development. Neuromotor dysfunction was classified as mild, moderate, or severe, based on the mobility of the child: mild if motor dysfunction was not severe enough to interfere with mobility, moderate if the child was independently mobile when provided with a hand to hold, and severe when the child was not independently mobile. ${ }^{10}$ Psychometric evaluations were performed at 24 and 36 months of age using the Scale of
Table 3 Growth outcome in preterm babies treated or not with dexamethasone

\begin{tabular}{lll}
\hline & $\begin{array}{l}\text { Treatment } \\
\text { group }(\mathrm{n}=15)\end{array}$ & $\begin{array}{l}\text { Control group } \\
(\mathrm{n}=15)\end{array}$ \\
\hline Mean age at follow up (months) & $36.6(1.7)$ & $36.2(0,6)$ \\
Mean body weight $(\mathrm{kg})$ & $12.732(2.184)$ & $12.422(1.738)$ \\
Below 3rd centile & $3(20)$ & $4(26.7)$ \\
3rd-97th centile & $12(80)$ & $11(73.3)$ \\
Above 97th centile & 0 & 0 \\
Mean body height $(\mathrm{cm})$ & $93.9(4.1)$ & $92.1(5.6)$ \\
Below 3rd centile & 0 & $2(13.3)$ \\
3rd-97th centile & $13(86.7)$ & $13(86.7)$ \\
Above 97th centile & $2(13.3)$ & 0 \\
Mean head circumference $(\mathrm{cm})$ & $48.6(1.4)$ & $48.5(2.3)$ \\
Below 3rd centile & $2(13.3)$ & $3(20)$ \\
3rd-97th centile & $13(86.7)$ & $12(80)$ \\
Above 97th centile & 0 & 0 \\
\hline
\end{tabular}

Values are expressed as number $(\%)$ or mean (SD)

Intelligence Stanford-Binet (3rd revised version of TermanMerrill). ${ }^{11}$ According to the intelligence quotient (IQ) score, children were subdivided into three groups: (1) IQ < 70; (2) IQ 70-90; (3) IQ > 90. Examiners, both paediatrician and paediatric neurologist, were completely blinded to group assignment.

For analysis of physical growth and developmental performance, the infant's postnatal age was corrected by the degree of prematurity before term (40 weeks). Anthropometric measurements were plotted on the growth chart for Italian children.

Differences in outcome were analysed using the $\chi^{2}$ Yates test for categorical variables or the Mann-Whitney $U$ test for continuous variables. $\mathrm{p}<0.05$ was considered significant.

\section{RESULTS}

The mean (SD) corrected postnatal age at the time of follow up was 36.6 (1.7) months for the treatment group and 36.2 (0.6) months for the control group. The incidence of readmission was $40 \%(6 / 15)$ in the dexamethasone group and $67 \%$ $(10 / 15)$ in the control group; the difference was not statistically significant. Two babies in the control group and five treated babies required repeated admissions. The main reason for readmission was the occurrence of bronchiolitis, pneumonia, and asthma. Two babies in each group needed surgical intervention for inguinal hernia.

Table 3 reports growth outcome in the babies studied. There were no significant differences between treated and control groups with regard to mean body weight, height, and head circumference. Data on body weight, height, and head circumference were plotted, based on the corrected age, on the growth chart for Italian children. There was no significant difference between the two study groups with respect to the incidence of infants with body weight, height, or head circumference in the normal range (3rd-97th centile) for corrected age. Three infants in the treated group and four in the control group had body weight below the 3rd centile. No baby in the dexamethasone treated group and two in the control group had height below the 3rd centile. Two treated and three control infants had head circumference below the third centile.

Table 4 presents data on neurodevelopmental outcome. At 12 months of corrected age, three infants in the treated group $(20 \%)$ and three in the control group $(20 \%)$ showed major cranial ultrasound abnormalities, diagnosed as periventricular leucomalacia or persistent ventricular dilatation. Cerebral palsy was diagnosed in two treated and three control babies; in all cases this was associated with major cranial ultrasound abnormalities. Major neurosensory impairment was observed 
Table 4 Neurodevelopmental outcome in preterm babies treated or not with dexamethasone

\begin{tabular}{lll}
\hline & $\begin{array}{l}\text { Treatment } \\
\text { group }(\mathrm{n}=15)\end{array}$ & $\begin{array}{l}\text { Control } \\
\text { group }(\mathrm{n}=15)\end{array}$ \\
\hline $\begin{array}{l}\text { Major cranial ultrasound } \\
\text { abnormalities at 12 months of }\end{array}$ & $3(20)$ & $3(20)$ \\
corrected age & & \\
Periventricular leucomalacia & $1(6.7)$ & 0 \\
Persistent ventricular dilatation & $2(13.3)$ & $3(20)$ \\
Cerebral palsy & $2(13.3)$ & $3(20)$ \\
Spastic quadriplegia & $1(6.7)$ & $2(13.3)$ \\
Spastic hemiplegia & $1(6.7)$ & 0 \\
Ataxia & 0 & $1(6.7)$ \\
Major neurosensory impairment & $4(26.7)$ & $4(26.7)$ \\
Blind & $1(6.7)$ & $1(6.7)$ \\
Poor vision & $2(13.3)$ & 0 \\
Severe deafness & 0 & $2(13.3)$ \\
Moderate hearing loss & $1(6.7)$ & $1(6.7)$ \\
Mean IQ Score (SD) & $84.2(12.4)$ & $83.0(15.6)$ \\
$>90$ & $5(33.3)$ & $8(53.3)$ \\
$70-90$ & $8(53.3)$ & $4(26.7)$ \\
$<$ - 70 & $2(13.3)$ & $3(20)$ \\
Behavioural abnormalities & $5(33.3)$ & $4(26.7)$ \\
\hline
\end{tabular}

Values are expressed as number (\%) or mean (SD).

in four infants $(27 \%)$ in each group. One infant from each group was blind and two treated babies had poor vision. Visual impairment was always due to severe retinopathy of prematurity, and, in one baby, it was also associated with periventricular leucomalacia and cerebral palsy. Two control infants showed severe deafness; this was secondary to acquired cytomegalovirus infection in the first case and associated with mental retardation and persistent ventricular dilatation in the second case. Moderate hearing loss was observed in one treated infant (apparently without cause) as well as in one control infant (associated with cranial ultrasound abnormality and cerebral palsy). The mean (SD) IQ score was 84.2 (12.4) for the treated group and 83.0 (15.6) for the control group. The proportion of infants with IQ score $>90$ was similar in both groups, while IQ score was $<70$ for two children in the treatment group and three control infants. Behavioural abnormalities were observed in five treated $(33 \%)$ and four control $(27 \%)$ infants.

\section{DISCUSSION}

Several studies have reported short term beneficial effects of postnatal steroid treatment in preterm infants at high risk of CLD. ${ }^{12}$ Although short term adverse effects such as hyperglycaemia, hypertension, growth impairment, cardiac hypertrophy, gastrointestinal bleeding and perforation, sepsis, and periventricular leucomalacia have been reported, ${ }^{12-16} \mathrm{few}$ published trials have been designed to evaluate the long term follow up effects in treated infants. Recent reports have raised concern that postnatal steroids may cause neurodevelopmental impairment in preterm infants. ${ }^{1-3} 6^{17}$

We report the three year follow up findings in preterm infants included in a randomised clinical trial of moderately early postnatal dexamethasone treatment. In a previous paper reporting growth data from birth to discharge, we showed that treated infants had a significantly smaller gain in weight and head circumference than controls only during the dexamethasone administration, without significant differences at 41 weeks of postmenstrual age. ${ }^{15}$ Our follow up data fail to show any negative effect of moderately early postnatal steroid administration on physical growth, as documented by data on body weight, height, and head circumference at 3 years of corrected age.

The three year neurodevelopmental outcome in the study groups was similar. It has to be emphasised that cerebral palsy was always associated with major cranial ultrasound abnormalities, visual impairment was secondary to severe retinopathy of prematurity, and compromised hearing was due to cytomegalovirus infection or cerebral damage, except in one treated baby. Mean IQ scores were similar in both treated and control infants, except that a higher incidence of infants with IQ score between 70 and 90 was observed in the treated group.

Available published data on the real risk of long term adverse effects of postnatal steroid treatment in preterm infants are not unequivocal. Some studies ${ }^{18-22}$ reported similar outcomes for treated and untreated infants, but recent reports ${ }^{1-3}$ have documented a higher incidence of neuromotor dysfunction and increased risk of cerebral palsy in treated babies. However, published studies are often conditioned by differences in confounding factors between study groups, ${ }^{2}{ }^{19}$ contamination of randomisation schedules, ${ }^{1}$ or too short a follow up period. ${ }^{18} 2022$ Looking at the data from Murphy et $a l^{5}$ showing a reduction in cortical grey matter volume in treated infants studied by magnetic resonance imaging techniques, one could argue that preterm infants exposed to dexamethasone were significantly smaller (757 (112) v 1259 (218) g), more immature $(25.4$ (2.0) $v 28.8$ (1.5) weeks), and affected by more severe respiratory disease than untreated infants. Two studies reporting a higher incidence of neuromotor dysfunction and an increased risk of cerebral palsy ${ }^{12}$ included babies treated with high doses of dexamethasone for a very long time ( 28 days from the first day of life and 42 days from the 3rd week after birth). More recently, Shinwell et al ${ }^{3}$ reported follow up data obtained for 159 of 190 infants included in a randomised, double blind, placebo controlled study, and concluded that a three day course of dexamethasone (total dose $1.5 \mathrm{mg} / \mathrm{kg}$ ) administered shortly after birth in preterm infants with respiratory distress syndrome is associated with a significantly increased incidence of cerebral palsy and developmental delay. In our study, infants were treated with a total dexamethasone dose of $4.75 \mathrm{mg} / \mathrm{kg}$ over 14 days from the 10th day of life. The two study groups of our trial were well matched with respect to all clinical data except for incidence of CLD, and results were not influenced by contamination of randomisation schedules because five infants of each group received two doses of $0.5 \mathrm{mg} / \mathrm{kg}$ dexamethasone to facilitate weaning from mechanical ventilation after the first month of life. Although our results do not show any severely negative effect due to dexamethasone treatment on long term growth and neurodevelopmental outcome, some possible limitations of our study should be outlined. Firstly, the sample size was calculated on the basis of the incidence of CLD in our high risk population to detect the reduction of CLD in treated infants and was thus probably insufficiently powered to detect small but significant differences in rare adverse outcome. Secondly, it is difficult to compare our results with those reported by authors who used different schedules for steroid treatment, and it is possible that doses higher than ours could be more dangerous for preterm infants, even if this hypothesis is not in agreement with the results obtained by Shinwell et $\mathrm{al}^{3}$ in a larger trial. In conclusion, the alarm raised about the potential detrimental effect of postnatal steroids on brain growth and developmental outcome should not be ignored and such treatment should be restricted to preterm infants with the highest risk of severe CLD on the basis of a risk/benefit ratio. The full extent of the risk will only be known when more trials have reported follow up data.

\section{Authors' affiliations}

C Romagnoli, E Zecca, R Luciano, G Tortorolo, Division of Neonatology, Catholic University of the Sacred Heart, Rome, Italy G Torrioli, Division of Child Neurology, Catholic University of the Sacred Heart 


\section{REFERENCES}

1 Yeh TF, Lin YJ, Huang CC, et al. Early dexamethasone therapy in preterm infants: a follow-up study. Pediatrics 1998 101:E7

(www.pediatrics.org/cgi/content/full/101/5/e7)

2 O'Shea TM, Kothadia JM, Klinepeter KL, et al. Randomized

placebo-controled trial of a 42-day tapering course of dexamethasone to reduce the duration of ventilator dependency in very low birth weight infants: outcome of study participants at 1 -year adjusted age. Pediatrics 1999:104:15-21.

3 Shinwell ES, Karplus M, Reich D, et al. Early postnatal dexamethasone treatment and increased incidence of cerebral palsy. Arch Dis Child Fetal Neonatal Ed 2000;83:F177-81.

4 Edwards HE, Burnham WM. The impact of corticosteroids on the developing animal. Pediatr Res 2001;50:433-40.

5 Murphy BP, Inder TE, Huppi PS, et al. Impaired cerebral cortical gray matter growth after treatment with dexamethasone for neonatal chronic lung disease. Pediatrics 2001;107:217-21.

6 Barrington K J. The adverse neurodevelopmental effects of postnatal steroids in the preterm infant: a systematic review of RCTs. BioMed Central Pediatr 2001:1:1. http://www.biomedcentral.com/1471$2431 / 1 / 1$

7 Romagnoli C, Vento G, Zecca E, et al. II Desametazone nella prevenzione della patologia polmonare cronica del neonato pretermine: studio prospettico randomizzato. Riv Ital Pediatr 1998:24:283-8.

8 Romagnoli C, Zecca E, Tortorolo L, et al. A scoring system to predict the evolution of respiratory distress syndrome into chronic lung disease in preterm infants. Intens Care Med 1998;24:476-80.

9 Stewart AL, Reynolds EOR, Hope HL, et al. Probability of neurodevelopmental disorders estimated from ultrasound appearance of brains of very preterm infants. Dev Med Child Neurol 1987;29:3-11.

10 Surveillance of cerebral palsy in Europe; a collaboration of cerebral palsy surveys and registers. Dev Med Child Neurol 2000;42:816-24.
11 Bozzo MT, Mansueto Zecca G. Scala di Intelligenza Stanford-Binet forma L-M (III revisione di Terman LM e Merril MA). O.S. Firenze: Organizzazione Speciali, 1986.

12 Holliday HL, Ehrenkranz RA. Moderately early (7-14 days) postnatal corticosteroids for preventing chronic lung disease in preterm infants. Cochrane Database Syst Rev 2000;2:CD001 144.

13 Holliday HL, Ehrenkranz RA. Early postnatal (<96 hours) corticosteroids for preventing chronic lung disease in preterm infants. Cochrane Database Syst Rev 2000;2:CD00 1146.

14 Stark AR, Carlo WA, Tyson JE. Adverse effects of early dexamethasone treatment in extremely-low-birth-weight infants. N Engl J Med 2001;344:95-101.

15 Romagnoli C, Zecca E, Vento G, et al. Effect on growth of two different dexamethasone courses for preterm infants at risk of chronic lung disease. Pharmacology 1999;59:266-74

16 Zecca E, Pappacci P, Maggio L, et al. Cardiac adverse effects of early dexamethasone treatment in preterm infants: a randomized clinical trial. $J$ Clin Pharmacol 2001:41:1075-81.

17 Barrington KJ. Postnatal steroids and Neurodevelopmental outcomes: a problem in the making. Pediatrics 2001;107:1425-6.

18 Mammel MC, Fiterman C, Coleman M, et al. Short term dexamethasone therapy for bronchopulmonary dysplasia: acute effects and one year follow up. Dev Pharmacol Ther 1987;10:1-11

19 Cummings JJ, D'Eugenio DB, Gross SK. A controlled trial of dexamethasone in preterm infants at high risk of bronchopulmonary dysplasia. N Engl J Med 1989;320:1505-10

20 O'Shea TM, Kothadia JM, Klinepeter KL, et al. Follow up of preterm infants treated with dexamethasone for chronic lung disease. American Journal of Diseases in Children 1993;147:658-61.

21 Jones R, Wincott E, Elbourne D, et al. Controlled trial of dexamethasone in neonatal chronic lung disease. A 3 year follow up. Pediatrics 1995;96:897-906

22 Ferrara TB, Courser RJ, Hoekstra RE. Side effects and long-term follow-up of corticosteroid therapy in very low birthweight infants with bronchopulmonary dysplasia. J Perinatol 1990;10:137-42.

\section{Call for peer reviewers}

Clinical Evidence is a regularly updated evidence based journal available world wide both as a paper version and on the internet. Clinical Evidence urgently needs to recruit a number of new contributors. Contributors are health care professionals or epidemiologists with experience in evidence based medicine and the ability to write in a concise and structured way.

Clinical Evidence needs to recruit a number of new peer reviewers. Peer reviewers are health care professionals or epidemiologists with experience in evidence based medicine. As a peer reviewer you would be asked for your views on the clinical relevance, validity and accessibility of specific topics within the journal, and their usefulness to the intended audience (international generalists and health care professionals, possibly with limited statistical knowledge). Topics are usually 2000-3000 words in length and we would ask you to review between 2-5 topics per year. The peer review process takes place throughout the year, and our turnaround time for each review is ideally 10-14 days.

If you are interested in becoming a peer reviewer for Clinical Evidence, please complete the peer review questionnaire at www.clinicalevidence.com or contact Polly Brown (pbrown@bmigroup.com). 